\title{
The Influence of Rootstock on the Growth and Fructification of Cherry Cultivars in a High Density Cultivation System
}

\author{
Monica Diana PAL ${ }^{1}$, Ioana MITRE ${ }^{1}$, Adrian C. ASĂNICĂ $\breve{2}^{2}$ \\ Adriana F. SESTRAȘ ${ }^{1}$, Adrian G. PETICILA $\breve{2}^{2}$, Viorel MITRE ${ }^{1 *}$ \\ ${ }^{1}$ University of Agricultural Sciences and Veterinary Medicine, Faculty of Horticulture, 3-5 Mănăștur Street, 400372 Cluj-Napoca, \\ Romania; pal.monicadiana@gmail.com; adriana.sestras@usamvcluj.ro; mitreviorel@yahoo.com (*correspondingauthor) \\ ${ }^{2}$ University of Agronomic Sciences and Veterinary Medicine, Faculty of Horticulture, 59 Marasti Blvd., District 1, 011464 Bucharest, \\ Romania; asanica@gmail.com; apeticila@yahoo.com
}

\begin{abstract}
The influence of rootstock on the growth and fruiting of three sweet cherry cultivars ('Bigarreau Burlat', 'Kordia', 'Regina') was studied under the pedoclimatic conditions of Cluj-Napoca, Romania, in 2014-2016. The trees were grafted on Gisela 5 rootstock, trained as Zahn Spindle and the orchard had a density of 1666 trees/ha. Root were cut twice, at $50 \mathrm{~cm}$ distance from the trunk, in an angle of $45^{\circ}$ and $30 \mathrm{~cm}$ depth, as followed: first time, to the autumn, in fall leaves time, on one side of the row and the second time, in spring, at blooming time, at the other side of the row. The rootstocks influenced height of the trees, the shoot growth, the number of long and fruiting branches, trunk cross sectional area yield and precocity, with differences statistically assured. The longest shoots, in mean values, gave the variant with cultivars grafted on Mahaleb rootstock (111.7 $\mathrm{cm})$. 'Gisela 5' rootstock decreases the average length of annual growth $(93.3 \mathrm{~cm})$. Trees grafted on Mahaleb formed more long fruiting branches and fewer short fruiting branches than those grafted on 'Gisela 5'. The biggest average trunks cross sectional area were obtained for the cultivars grafted on Mahaleb $\left(62.1 \mathrm{~cm}^{2}\right)$. Also rootstocks influenced the height of the trees. The cumulative yield was almost double in variants where the trees were grafted on 'Gisela 5' (23.2kg/tree), compared to the variants where the trees were grafted on Mahaleb $(13.1 \mathrm{~kg} / \mathrm{tree})$.
\end{abstract}

Keywords: rootstock, vegetative growth, fruiting, yield, trunk cross-sectional area

\section{Introduction}

In the last years, there has been an interest of cultivating new varieties of sweet cherries grafted on dwarf cherry rootstock (Lang, 2001). This has allowed developing highdensity orchards with smaller vigour trees that are more productive and more precocious (Andersen et al., 1999).

Mahaleb (Prunus mahaleb L.) seedling is one of a traditional rootstock used for sweet cherry production. Cherry trees grafted on these rootstocks are vigorous and difficult to maintain, especially during harvesting (Gyeviki et al., 2008). In the last few years, farmers have shown an increased interest for new high density cherry orchards established on dwarfing rootstock. The Gisela 5 cherry rootstock is among the best dwarfing, precocious, and productive rootstocks for modern intensive sweet cherry growing (Zimmermann, 1994).

Maintaining an optimal balance between growth and fruiting is an ongoing concern of research in fruit growing.
Besides the classical methods of reducing the vigor (low vigor rootstocks and cultivars, compact types, pruning in green, balanced fertilization etc.) cutting root in order to reduce growth vigor and increase the number of fruit formation is increasingly more used. Performance of a culture system of fruit trees are largely related to creating an optimal balance between growths and fruiting. Luxuriant vegetative growth delay the shade crown for entry bearing trees and reduce yield and fruit quality (Mitre et al., 2012).

In high-density cherry orchard, otherwise as in any fruit growing culture, the vegetative growth must temperate and turn them as bearing branches or as branches support. In addition, the vegetative growth must be balanced with flowering (Hugard, 1980; Sharma et al., 2009; Walker, 1980).

The maintenance of properly equilibrium between the vegetative and reproductive processes is a major challenge in tree fruit production (Sharma et al., 2009). There are many horticultural ways to keep a permanent balance between growth and fruiting: rootstocks (who control directly 
452

vegetative growth), dormant pruning, summer pruning, root pruning, branches orientation, scoring, girdling and bark inversion, plant growth regulators, deficit irrigation, fertilization, but to date none have proven to be universally successful (Sharma et al., 2009). Rootstocks have provided apple growers with trees of reduced stature suited to a wide range of planting densities (Faust, 1989) but are partially successful in controlling excess growth (Sharma et al., 2009). Limiting the uptake of water and nutrients can be achieved through manipulating root systems of fruit trees.

The aim of this research was to provide information about the growth parameters (height of trees, length of shoots, trunk sectional area), capacity of forming fruiting branches and fructification yield and cumulative yield, for 2014-2016 period, of the three cherry cultivars, grafted on two different rootstocks (Mahaleb and 'Gisela 5').

\section{Materials and Methods}

\section{Location and orchard density}

The research has been carried out at a sweet cherry orchard, set up in spring of 2012 at Cluj-Napoca, in the centre of Transylvania (Romania). The planting system chosen for the experimental plot was $4 \mathrm{~m}$ between rows and $1.5 \mathrm{~m}$ between trees within row, resulting a high density orchard with 1666 trees/ha.

\section{Sampling design and cultivars}

The experience was a bifactorial one: first experimental factor was the rootstock (Mahaleb and 'Gisela 5') and the second one the cultivar ('Bigarreau Burlat', 'Kordia' and 'Regina'). In order to correspond to such a bifactorial model, there were formed 18 experimental plots comprising the 6 variants $(2 \times 3)$ in three replicates. For the experiment, sweet cherry trees were grafted on 'Gisela 5' rootstock. Vegetative and reproductive growth parameters (length of shoots, trunk sectional area, height of trees, the number of long fruiting branches, the number of short fruiting branches) were determined in the autumn of each experimental year, after the leaves fall down.

\section{Cultural management of the plantation}

The technology of culture was a specific one to the sweet cherry high density orchard. The orchard was assisted by fertigation and antihail systems. Roots were cut mechanically twice, at $50 \mathrm{~cm}$ distance from the trunk, in an angle of 45 grade and $30 \mathrm{~cm}$ depth, as followed: first time, in the autumn fall leaves on one side of the row and the second time, inspring, before blooming time on the other side of the row.

\section{Statistical procedures}

Processed data are presented in mean values on the three years of research. The results obtained were processed using analysis of variance and Duncan's multiple range test (DMRT, or Duncan's test) was used in order to provides significance levels for the difference between pair of means, regardless of whether a significant $F$ resulted from an initial analysis of variance. The differences among treatments means were compared at $5 \%$ probability.

\section{Results and Discussion}

In the high density cherry growing, keeping trees in an optimum balance between grow and fruiting is the most important challenge. Therefore, the comparative study of the response of some cultivars of cherry grafted on two rootstocks of different groups of vigour in a high density cherry cultivation system is justified.

\section{Vigor of the cherry trees}

Data of the Table 1 presents the influence of the rootstocks and the cultivars on the vigor of cherry trees expressed by tree height, shoots length and trunk sectional area.

Regarding the tree height one can say that the highest value of the height of the trees was registered in 'Bigarreau Burlat' cultivar $(403.0 \mathrm{~cm})$. It has to be underlined that 'Kordia' and 'Regina' behaved similarly from the statistically point of view. As expected, the biggest value of trees height was obtained in the variant with trees grafted on mahaleb $(389.7 \mathrm{~cm})$ even if rootstock roots were cut mechanically and the lowest in the variant with trees grafted on 'Gisela 5' $(364.3 \mathrm{~cm})$, phenomenon explained due to the difference in vigor between the two rootstocks. A similar opinion was expressed by Santos et al. (2006), and Cmelik et al. (2002), studying the influence of the 'Gisela 5' rootstock on the average height of cherry varieties. Aglar and Yildiz (2014), indicated that '0900 Ziraat' variety grafted on 'SL 64 ' had bigger height of trees and crown volume than those grafted on 'Gisela 5'. Also in the experiment conducted by the same author, Aglar et al. (2016), mentioned that the tall of trees on 'MaxMa 14' were higher than these on 'Gisela 5' and 'Gisela 6' rootstocks.

Data of the second column of the table show an important influence of the rootstock and the cultivar on the average length of annual growth. The longest shoots, in mean value was registered for the cultivars grafted on Mahaleb rootstock (111.7 cm), while 'Gisela 5' decrease the average length of annual shoots $(93.3 \mathrm{~cm})$. The highest value of shoots average was registered in 'Bigarreau Burlat' $(115.0 \mathrm{~cm})$, followed by 'Kordia' $(98.0 \mathrm{~cm})$ and the shortestvalue of this parameter was registered in 'Regina' $(94.5 \mathrm{~cm})$. Asănică et al. (2011a) reported different number of long fruiting branches that formed 'Kordia'.

The shoots having optimal length, especially in the early stages of the trees, are an important indicator of growth and fruit production of the future plantation but also achieve a balance between two processes; also annual branches placed in the right position helps form a strong framework of branches, allows air and light into the tree, induces flower and fruit bud formation, restricts tree size and maintains a balanced shape (Mitre et al., 2012).

It can be observed that the longest shoots were obtained on 'Bigarreau Burlat' grafted on Mahaleb $(128.0 \mathrm{~cm})$ and the shortest shoots at 'Regina' grafted on 'Gisela 5' (88.3 $\mathrm{cm})$.

Excessive vegetative growth reduces flowering and ultimately fruiting (Forshey and Elfving, 1989; Luckwill, 1970). A certain amount of growth is necessary to maintain vigor and healthy bearing canopy with an adequate leaf surface (Sharma et al., 2009). Musacchi et al. (2015) 
obtained less vegetative growth of 'Kordia' and 'Regina' grafted on 'Gisela 5'.

In the third column of the table are presented data regarding to the influence of the rootstocks and the cultivars on average trunk sectional area. It can be seen that 'Bigarreau Burlat' registered the biggest value of this character $\left(69.7 \mathrm{~cm}^{2}\right)$. Data of the table shows that the biggest average trunks cross sectional area were obtained in the variant with the cultivars grafted on Mahaleb (62.1 $\mathrm{cm}^{2}$ ). The smallest trunk cross sectional area was registered in the variant where the trees were grafted on 'Gisela 5' $\left(50.9 \mathrm{~cm}^{2}\right)$. The biggest average trunk cross sectional area was registered with 'Bigarreau Burlat' grafted on Mahaleb $\left(69.7 \mathrm{~cm}^{2}\right)$ and the smallest one with 'Regina' grafted on 'Gisela 5' $\left(46.3 \mathrm{~cm}^{2}\right)$ looking to the combined interaction of the two experimental factor.

Similar results were obtained by other authors concerning the influence of 'Gisela 5' on the trunk section area. Musacchi et al. (2015) reported that the smaller values for 'Kordia' and 'Regina', but Gjamovski et al. (2016) recorded similar values for the same cultivars. The results of the trunk section area of 'Gisela 5' rootstock were similar with the values recorded by Drkenda et al. (2012) for 'Bigarreau Burlat' and Milinović et al. (2016) for 'Kordia' and 'Regina'. These results are in accordance with the data obtained earlier by Tomaszewska and Nychnerewicz (2006) regarding the influence of 'Gisela 5' rootstock on trunk section area of 'Bigarreau Burlat', 'Kordia', 'Regina' and 'Van' cultivars in a high density orchard. Also, these results are in agreement with Bielicki and Rozpara (2010), who reported similar results about the influence of 'Gisela 5' rootstock on the trunk cross-sectional area of the 'Kordia' sweet cherry cultivar in the $5^{\text {th }}$ year after planting.

\section{Reproductive growth potential}

In the Table 2 are presented data regarding the influence of rootstock and the cultivar on the number of long and short fruiting branches. During the formation and maintenance of the tree crowns, a very important aspect is on the one hand to maintain the optimal balance between growing and fruit production and on the other hand, to create as many branches of fruit as possible. Regarding the influence of the cultivar on the number of long fruiting branches, data of Table 2 show that, regardless the influence of rootstocks, there are differences statistically assured only between all three cultivars. Regardless the cultivar, the lowest number of long fruiting branches was registered in cherry trees grafted on Mahaleb (42.1) and the biggest number was obtained for cherry cultivars grafted on 'Gisela 5 ' (64.0). Taking into account of the combined interaction of the two experimental factor, the biggest number of long fruiting branches were obtained in 'Kordia' grafted on 'Gisela 5' (72.9), and the lowest value was registered in the same cultivar, 'Bigarreau Burlat', grafted on Mahaleb (36.7).

Asănică et al. (2011a), studding 'Skeena', 'Kordia' and 'Ferrovia' sweet cherry cultivars grafted on 'Gisela 5' rootstock in the first year after planting, reported that 'Kordia' has formed the largest number of long branches on the tree (18.7).

Regarding the influence of the cultivar on the average number of short fruiting branches, the cultivars behaved differently from statistically point of view. The biggest number of short fruiting branches was obtained at 'Kordia' (132.5) followed by 'Regina' (124.5) and 'Bigarreau Burlat' (111.6). Concerning the influence of the rootstock, the biggest value of this parameter was registered for the cherry cultivars grafted on 'Gisela 5' (148.6), and the lowest value was obtained in trees grafted on Mahaleb (91.7). A similar opinion was expressed by Asănică $e t$ al. (2011b) who found a significantly difference regarding the number of long and short fruit branches depending of cultivar and rootstock, starting from the second year after planting.

The smallest number of short fruiting branches was obtained by 'Bigarreau Burlat' grafted on 'Gisela 5' (86.7) and the biggest number was registered for 'Kordia' grafted on Mahaleb (164.9).

Table 1. Influence of the rootstock and the cultivar on the vigor of cherry tree expressed by tree height, shoots length and trunk sectional area

\begin{tabular}{|c|c|c|c|c|}
\hline Rootstock & Cultivar & $\begin{array}{l}\text { Tree height } \\
(\mathrm{cm})\end{array}$ & $\begin{array}{l}\text { Shoots length } \\
(\mathrm{cm})\end{array}$ & $\begin{array}{l}\text { Trunk sectional area } \\
\qquad\left(\mathrm{cm}^{2}\right)\end{array}$ \\
\hline \multirow{3}{*}{ Mahaleb } & 'Bigarreau Burlat' & $403.0^{\mathrm{a}}$ & $128.0^{a}$ & $69.7^{a}$ \\
\hline & 'Kordia' & $385.7^{b}$ & $106.3^{b}$ & $59.2^{b}$ \\
\hline & 'Regina' & $380.3^{b}$ & $100.7^{b}$ & $57.3^{b}$ \\
\hline \multirow{3}{*}{ 'Gisela 5’ } & 'Bigarreau Burlat' & $378.3^{b}$ & $102.0^{\mathrm{b}}$ & $59.4^{b}$ \\
\hline & 'Kordia' & $355.7^{c}$ & $89.7^{c}$ & $46.9^{c}$ \\
\hline & 'Regina' & $359.0^{c}$ & $88.3^{c}$ & $46.3^{c}$ \\
\hline & Mean Rootstock & & \\
\hline \multicolumn{2}{|c|}{ Mahaleb } & $389.7^{\mathrm{M}}$ & $111.7^{\mathrm{M}}$ & $62.1^{\mathrm{M}}$ \\
\hline \multicolumn{2}{|c|}{ 'Gisela 5’ } & $364.3^{N}$ & $93.3^{\mathrm{N}}$ & $50.9^{\mathrm{N}}$ \\
\hline & Mean cultivar & & \\
\hline \multicolumn{2}{|c|}{ 'Bigarreau Burlat' } & $390.7^{\mathrm{A}}$ & $115.0^{\mathrm{A}}$ & $64.6^{A}$ \\
\hline \multicolumn{2}{|c|}{ 'Kordia' } & $370.7^{\mathrm{B}}$ & $98.0^{\mathrm{B}}$ & $53.0^{\mathrm{B}}$ \\
\hline \multicolumn{2}{|c|}{ 'Regina' } & $369.7^{\mathrm{B}}$ & $94.5^{\mathrm{B}}$ & $51.8^{\mathrm{B}}$ \\
\hline \multicolumn{2}{|c|}{ DS $5 \%$ Cultivar } & $5.5-5.8$ & & $1.8-1.9$ \\
\hline \multicolumn{2}{|c|}{ DS $5 \%$ Rootstock } & 4.5 & & 1.5 \\
\hline \multicolumn{2}{|c|}{ SD $5 \%$ Interaction $\mathrm{cv} . \times$ rootstock } & $7.8-8.6$ & & $2.6-2.9$ \\
\hline
\end{tabular}


Table 2. Influence of the rootstock and the cultivar on the number long and short fruiting branches

\begin{tabular}{|c|c|c|c|}
\hline Rootstock & Cultivar & Number of long fruiting branches & Number of short fruiting branches \\
\hline \multirow{3}{*}{ Mahaleb } & 'Bigarreau Burlat' & $36.7^{\mathrm{e}}$ & $86.7^{\mathrm{e}}$ \\
\hline & 'Kordia' & $45.5^{\mathrm{d}}$ & $100.2^{d}$ \\
\hline & 'Regina' & $44.1^{\mathrm{d}}$ & $104.5^{\mathrm{d}}$ \\
\hline \multirow{3}{*}{ 'Gisela 5' } & 'Bigarreau Burlat' & $56.4^{\mathrm{c}}$ & $136.4^{c}$ \\
\hline & 'Kordia' & $72.9^{\mathrm{a}}$ & $164.9^{a}$ \\
\hline & 'Regina’ & $62.6^{\mathrm{b}}$ & $144.4^{b}$ \\
\hline \multicolumn{4}{|c|}{ Mean rootstock } \\
\hline \multicolumn{2}{|c|}{ Mahaleb } & $42.1^{\mathrm{N}}$ & $91.7^{\mathrm{N}}$ \\
\hline \multicolumn{2}{|c|}{ 'Gisela 5’' } & $64.0^{\mathrm{M}}$ & $148.6^{\mathrm{M}}$ \\
\hline \multicolumn{4}{|c|}{ Mean cultivar } \\
\hline \multicolumn{2}{|c|}{ 'Bigarreau Burlat' } & $46.6^{\mathrm{C}}$ & $111.6^{\mathrm{C}}$ \\
\hline \multicolumn{2}{|c|}{ 'Kordia' } & $59.2^{\mathrm{A}}$ & $132.5^{\mathrm{A}}$ \\
\hline \multicolumn{2}{|c|}{ 'Regina' } & $53.4^{\mathrm{B}}$ & $124.5^{\mathrm{B}}$ \\
\hline \multicolumn{2}{|c|}{ DS $5 \%$ Cultivar } & $3.6-3.8$ & $5.3-5.5$ \\
\hline \multicolumn{2}{|c|}{ DS $5 \%$ Rootstock } & 3.0 & 4.3 \\
\hline \multicolumn{2}{|c|}{ SD $5 \%$ Interaction cv. $\times$ rootstock } & $5.1-5.7$ & $7.4-8.2$ \\
\hline
\end{tabular}

\section{Precocity and fruit yield evaluation}

Data of the Table 3 presents the influence of rootstock and cultivar on the yield of the cherry tree for each year of the analysed period. The results are all the more interesting as we analyze both the precocity of fruiting induced by the two rootstocks and the yield registered for each combination in the first three years of fruiting.

The data of Table 3 show a strong influence of the rootstock on the yielding precocity but also on the fruit production obtained during the first three years of fructification. Our results confirm those of Stehr (2005) that 'Gisela 5' enhances precocity. The yield for each analyzed year of experiment was almost double in variants where the trees were grafted on 'Gisela 5'.

The cherry trees grafted on mahaleb reached the production performance of the grafted on 'Gisela 5' barely a year later. The biggest productions have been recorded in 'Regina' and 'Kordia' during all three experimental years.

The fruit size is an important characteristic for commercial market value (Vittrup Christensen, 1995). Pérez-Sánchez et al. (2010) indicated that fruit weight is the most important physical of the fruit, upon which the fruit value (price) depends. Fruit size from the trees on 'Gisela 5' rootstock depends on crop load and soil moisture (Vercammen 2002; Vercammen et al., 2006). Dry periods during some growth seasons and climate conditions might also affect fruit size. But a strong influence on the size of the fruit is given by variety and rootstock.

Data of the Table 4 show that fruits diameter and weight was strongly influenced by rootstock in the sense that the biggest fruits diameter on 'Gisela 5' rootstock was registered and the smallest on Mahaleb. Regardless the rootstock, between the three cultivars there were differences statistically assured, the biggest fruit diameter was registered at 'Regina' $(27.5 \mathrm{~mm})$, followed by 'Kordia' $(26.4 \mathrm{~mm})$ and 'Bigarreau Burlat' $(25.1 \mathrm{~mm})$. Regarding the fruits weight the results were quite similar that in case of those of fruits diameter.

Data concerning the influence of the rootstock and the cherry cultivar upon cumulative yield of 2014-2016 growing seasons are presented in Fig. 1. It can be seen that the best cumulative yield in mean value was obtained in variants of cultivars grafted on 'Gisela 5' $(23.2 \mathrm{~kg} / \mathrm{tree})$ followed by the system where cherry trees are grafted on Mahaleb $(13.1 \mathrm{~kg} /$ trees $)$ with differences statistically assured between these two variants.

Regardless the treatment only between 'Regina', 'Kordia' and 'Bigarreau Burlat' there is differences statistically assured. The best cumulative yield gave 'Regina' ( $7.6 \mathrm{~kg} / \mathrm{tree})$ and the lowest 'Bigarreau Burlat' ( $5.6 \mathrm{~kg} / \mathrm{tree})$.

Regarding the combined influence of two experimental factors, the best cumulative yield was obtained at 'Regina' grafted on 'Gisela 5' (20.2 kg/tree) followed by 'Kordia' grafted on 'Gisela 5' (19.4 kg/tree) and the lowest cumulated yield was obtained in the variant on 'Bigarreau Burlat' grafted on Mahaleb (10.2 kg/tree).

Cumulative yield is by far the most important indicator that reflects the performance of orchards (Mitre et al., 2012). Similar results were obtained by Musacchi et al. (2015), regarding the influence of 'Gisela 5 ' on the cumulative yield of 'Kordia' and 'Regina'. The results of average yield of 'Gisela 5' rootstock are slightly bigger than the results reported by Usenik et al. (2010). The same results was reported by Tomaszewska and Nychnerewicz (2006), studying the influence of 'Gisela 5' on the cumulative yield of 'Bigarreau Burlat', 'Kordia' and 'Regina'. It is important to note that other authors (Sitarek et al., 2005; Rozpara and Grzyb, 2006; Gyeviki et al., 2008) reported negative effects of dwarfing rootstocks on cumulative yield. Less cumulative yield of 'Gisela' rootstock towards to Mahaleb stocks selected at Department of Fruit Growing of Corvinus University of Budapest ('Bogdány', 'Egervár', 'Magyar', 'SM 11/4', 'Korponay') was already described by Bujdosó and Hrotkó, (2012). Our results confirm those of Stehr (2005) that 'Gisela 5' enhances precocity. According to Bielicki and Rozpara (2010), the yield of 'Kordia' grafted on 'Gisela 5' in the $5^{\text {th }}$ year after planting, was $19.6 \mathrm{~kg} /$ tree. In order to have a more complete picture of the influence of the two rootstocks on the growth and fructification of the trees, research should be continued in the next years of yielding. 
Table 3. Influence of the rootstock and the cultivar on the yield of the cherry tree $(\mathrm{kg} / \mathrm{tree})$ in 2014-2016

\begin{tabular}{|c|c|c|c|c|}
\hline Rootstock & Cultivar & 2014 & 2015 & 2016 \\
\hline \multirow{3}{*}{ Mahaleb } & 'Bigarreau Burlat' & $1.6^{\mathrm{e}}$ & $3.6^{\mathrm{e}}$ & $5.0^{d}$ \\
\hline & 'Kordia' & $2.2^{\mathrm{d}}$ & $5.2^{d}$ & $6.8^{\mathrm{c}}$ \\
\hline & 'Regina' & $2.4^{\mathrm{d}}$ & $5.4^{\mathrm{d}}$ & $7.0^{\mathrm{c}}$ \\
\hline \multirow{3}{*}{ 'Gisela 5’ } & 'Bigarreau Burlat' & $3.7^{\mathrm{c}}$ & $7.7^{\mathrm{c}}$ & $8.2^{b}$ \\
\hline & 'Kordia' & $4.6^{b}$ & $9.3^{b}$ & $10.7^{a}$ \\
\hline & 'Regina' & $5.5^{\mathrm{a}}$ & $9.8^{\mathrm{a}}$ & $10.3^{\mathrm{a}}$ \\
\hline \multicolumn{5}{|c|}{ Mean rootstock } \\
\hline \multicolumn{2}{|c|}{ Mahaleb } & $2.1^{\mathrm{N}}$ & $4.7^{\mathrm{N}}$ & $6.2^{\mathrm{N}}$ \\
\hline \multicolumn{2}{|c|}{ 'Gisela 5’ } & $4.6^{\mathrm{M}}$ & $8.9^{\mathrm{M}}$ & $9.7^{\mathrm{M}}$ \\
\hline \multicolumn{5}{|c|}{ Mean cultivar } \\
\hline \multicolumn{2}{|c|}{ 'Bigarreau Burlat' } & $2.6^{\mathrm{C}}$ & $5.6^{\mathrm{C}}$ & $6.6^{\mathrm{B}}$ \\
\hline \multicolumn{2}{|c|}{ 'Kordia' } & $3.4^{\mathrm{B}}$ & $7.2^{\mathrm{B}}$ & $8.8^{\mathrm{A}}$ \\
\hline \multicolumn{2}{|c|}{ 'Regina' } & $4.0^{\mathrm{A}}$ & $7.6^{\mathrm{A}}$ & $8.7^{\mathrm{A}}$ \\
\hline \multicolumn{2}{|c|}{ DS 5\% Cultivar } & 0.5 & $0.4-0,5$ & 0.6 \\
\hline \multicolumn{2}{|c|}{ DS 5\% Rootstock } & 0.4 & 0.4 & 0.5 \\
\hline \multicolumn{2}{|c|}{ SD $5 \%$ Interaction $\mathrm{cv} . \times$ rootstock } & $0.7-0.8$ & $0.6-0.7$ & $0.8-0.9$ \\
\hline
\end{tabular}

${ }^{*}$ Note: Different letters between cultivars denote significant differences

Table 4. Influence of the rootstock and the cultivar on diameter $(\mathrm{mm})$ and weight $(\mathrm{g})$ of the fruits

\begin{tabular}{|c|c|c|c|}
\hline Rootstock & Cultivar & $\begin{array}{l}\text { Fruit diameter } \\
\qquad(\mathrm{mm})\end{array}$ & $\begin{array}{c}\text { Fruit weight } \\
\text { (g) }\end{array}$ \\
\hline \multirow{3}{*}{ Mahaleb } & 'Bigarreau Burlat' & $23.4^{\mathrm{c}}$ & 7.0 \\
\hline & 'Kordia' & $24.7^{\mathrm{c}}$ & 8.3 \\
\hline & 'Regina' & $25.7^{\mathrm{b}}$ & 9.2 \\
\hline \multirow{3}{*}{ 'Gisela 5’ } & 'Bigarreau Burlat' & $26.7^{\mathrm{b}}$ & 8.9 \\
\hline & 'Kordia' & $28.1^{\mathrm{a}}$ & 10.9 \\
\hline & 'Regina' & $29.3^{\mathrm{a}}$ & 11.1 \\
\hline \multicolumn{4}{|c|}{ Mean Rootstock } \\
\hline \multicolumn{2}{|c|}{ Mahaleb } & $24.6^{\mathrm{N}}$ & 8.2 \\
\hline \multicolumn{2}{|c|}{ 'Gisela 5' } & $28.1^{\mathrm{M}}$ & 10.3 \\
\hline \multicolumn{4}{|c|}{ Mean cultivar } \\
\hline \multicolumn{2}{|c|}{ 'Bigarreau Burlat' } & $25.1^{\mathrm{C}}$ & 8.0 \\
\hline \multicolumn{2}{|c|}{ 'Kordia’ } & $26.4^{\mathrm{B}}$ & 9.6 \\
\hline \multicolumn{2}{|c|}{ 'Regina' } & $27.5^{\mathrm{A}}$ & 10.2 \\
\hline \multicolumn{2}{|c|}{ DS 5\% Cultivar } & 1.3 & 0.4 \\
\hline \multicolumn{2}{|c|}{ DS $5 \%$ Rootstock } & 1.0 & 0.3 \\
\hline \multicolumn{2}{|c|}{ SD $5 \%$ Interaction cv. $\times$ rootstock } & $1.8-2.0$ & $0.5-0.6$ \\
\hline
\end{tabular}

"Note: Different letters between cultivars denote significant differences

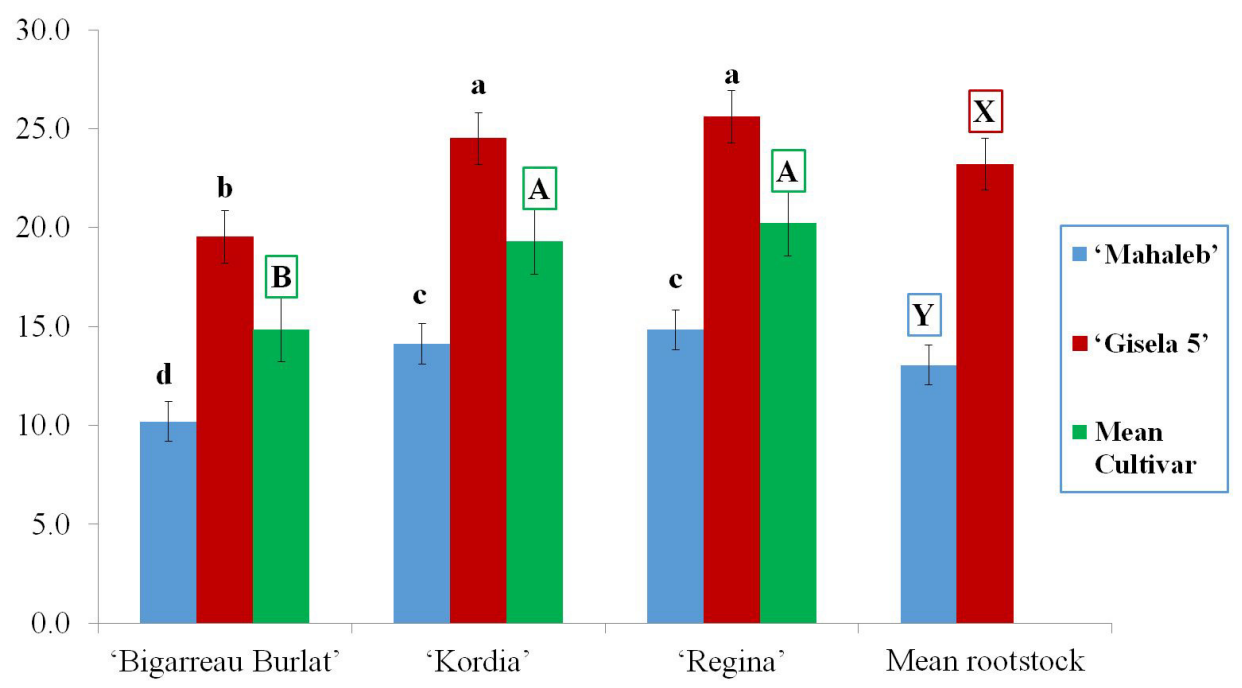

Fig. 1. Influence of the rootstock and the cultivar on cumulated yield in 2014-2016 (kg ha $\left.{ }^{-1}\right)$. Different letters between variants denote significant differences: DS $5 \%$ cultivar $=1.1-1.2$; DS 5\% rootstock=0.9; DS 5\% interaction cultivar $\times$ rootstock $=1.6-1.7$ 


\section{Conclusions}

Rootstock had a strong influence on growth and fructification of studied cherry cultivars in high density culture system. Mahaleb due to its vigour has induced more vigorous growth of the cherry trees expressed by tree height, length of annual branches, the section of the trunk, even if they proceeded to cut roots. Trees grafted on Mahaleb formed more less fruiting branches and fewer short fruiting branches than those grafted on 'Gisela 5'. Fruit yield, in the first three years of fruiting, was almost double in variants where the trees were grafted on 'Gisela 5', compared to the variants where the trees were grafted on mahaleb. Mahaleb as cherry rootstock in high density plantations delay the entry of trees into bearing fruit and induce smaller yields.

\section{Acknowledgements}

This work was supported by the Institute of Advanced Horticulture Research of Transylvania, University of Agricultural Sciences and Veterinary Medicine ClujNapoca.

\section{References}

Aglar E, Yildiz K (2014). Influence of rootstocks (Gisela 5, Gisela 6, MaxMa SL 64) on performance of '0900 Ziraat' sweet cherry. Journal of Basic and Applied Science 10:60.

Aglar E., Yildizand K, Long LE (2016). The effects of rootstocks and training systems on the early performance of ' 0900 Ziraat' sweet cherry. Notulae Botanicae Horti AgrobotaniciCluj-Napoca 44(2):573-578.

Andersen RL, Robinson TL and Lang GA (1999). Managing the Gisela cherry rootstocks, New York Fruit Quarterly 7(4):19-22.

Asănică A, Sumedrea D, Chitu E, Tanasescu N, Tudor V (2011a). Initial growth and yield of Skeena, Kordia and Ferrovia sweet cherry varieties on Gisela 5 rootstock. Bulletin UASMV Horticulture 68(1):77-82.

Asănică A, Tudor V, Grivu P, Temocico G (2011b). Evaluation of some sweet cherry cultivars on PHLC and CAB dwarfing rootstock in Istrita Buzau, Romania. Lucrări Științifice Universitatea de Științe Agronomice și Medicină Veterinară București. Seria B, Horticultură (55):346-351.

Bielicki P, Rozpara E (2010). Growth and yield of 'Kordia'sweet cherry trees with various rootstock and interstem combinations. Journal of Fruit and Ornamental Plant Research 18(1):45-50.

Bujdosó G, Hrotkó K (2012). Preliminary results on growth, yield and fruit size of some new precocious sweet cherry cultivars on Hungarian bred mahaleb rootstocks. Acta Horticulturae 1058:559564.

Christensen JV (1995). Evaluation of fruit characteristics of 20 sweet cherry cultivars. Fruit Varieties Journal 49(2):113-117.

Cmelik Z, Druzic J, Duralija B, Bencic D (2002). Influence of clonal rootstocks on growth and cropping of 'Lapins' sweet cherry. Acta Horticulturae 658:125-128.

Drkenda P, Spahic A, Spahic A, Begic-Akagic A (2012). Testing of
'Gisela 5' and 'Santa Lucia 64' cherry rootstocks in Bosnia and Herzegovina. Acta Agriculturae Slovenica 99(2):129.

Faust M (1989). Physiology of temperate zone fruit trees. John Wiley and Sons Ltd. New York, US.

Forshey CG, Elfving DC (1989). The relationship between vegetative growth and fruiting in apple trees. In: Janick J (Ed). Horticultural Reviews 11:229-287.

Gjamovski V, Kiptijanovski M, Arsov T (2016). Evaluation of some cherry varieties grafted on Gisela 5 rootstock. Turkish Journal of Agriculture and Forestry 40(5):737-745.

Gyeviki M, Bujdosó G and Hrotkó K (2008). Results of cherry rootstock evaluations in Hungary. International Journal of Horticultural Science 14(4):11-14.

Gyeviki M, Magyar L, Bujdosó G, Hrotkó K (2008). Cherry rootstock evaluation for high density orchards in Hungary. Bulletin UASMV Horticulture 65(1):231-236.

Hugard J (1980). High density planting in French orchards: development and current achievement. Acta Horticulturae 114:300-308.

Lang GA (2001). Intensive sweet cherry orchard systems-rootstock, vigor, precocity, productivity, and management. Compact Fruit Tree 34(1):23-26.

Luckwill LC (1970). The control of growth and fruitfulness of apple tree. In: Physiology of Tree Fruit Crops. Luckwill LC, Cutting CV (Eds). Academic Press. London.

Milinović B, Dragović-Uzelac V, Kazija DH, Jelačić T, Vujević P, Čiček D, Biško A, Čmelik Z (2016). Influence of four different dwarfing rootstocks on phenolic acids and anthocyanin composition of sweet cherry (Prunus avium L.) cvs 'Kordia' and 'Regina'. Journal of Applied Botany and Food Quality 89:29-37.

Mitre V, Mitre I, Sestras AF, Sestras RE (2012). Effect of root pruning upon the growth and fruiting of apple trees in high density orchards. Bulletin UASMV Horticulture 69(1-2):254-259.

Musacchi S, Gagliardi F, Serra S (2015). New training systems for highdensity planting of sweet cherry. HortScience 50(1):59-67.

Pérez-Sánchez R, Gómez-Sánchez MA, Morales-Corts MR (2010). Description and quality evaluation of sweet cherries culture in Spain. Journal of Food Quality 33(4):490-506.

Rozpara E, Grzyb ZS (2006). The effect of the 'Northstar' interstem on the growth, yielding and fruit quality of five sweet cherry cultivars. Journal of Fruit and Ornamental Plant Research 14:91-96.

Santos A, Santos-Ribeiro R, Cavalheiro J, Cordeiro V, Lousada JL (2006). Initial growth and fruiting of 'Summit' sweet cherry (Prunus avium) on five rootstocks. New Zeeland Journal of Crop and Horticultural Science 34(3):269-277.

Sharma S, Rehalia AS, Sharma SD (2009). Vegetative growth restriction in pome and stone fruits - A review. Agricultural Reviews 30(1):1323.

Sitarek M, Grzyb ZS, Koziński B (2005). The influence of different rootstocks on the growth and yield of sweet cherry trees during the first four years after planting in the double row system. Acta Horticulturae 795:531-536.

Stehr R (2005). Experiences with dwarfing sweet cherry rootstocks in 
Northern Germany. Acta Horticulturae 667:173-177.

Tomaszewska Z, Nychnerewicz B (2006). The effect of rootstock on growth and fruitage of sweet cherry. Scientific Works of the Lithuanian Institute of Horticulture and Lithuanian University of Agriculture 25(3):224-229.

Usenik V, Fajt N, Mikulic-Petkovsek M, Slatnar A, Stampar F, Veberic $\mathrm{R}$ (2010). Sweet cherry pomological and biochemical characteristics influenced by rootstock. Journal of Agricultural and Food Chemistry 58(8):4928-4933.
Vercammen J, Van Daele G, Vanrykel T (2006). Use of Gisela 5 for sweet cherries. Scientific Works of the Lithuanian Institute of Horticulture and Lithuanian University of Agriculture 25:218-223.

Vercammen J (2002). Dwarfing rootstocks for sweet cherries. Acta Horticulturae 658:307-311.

Walker CD (1980). The development of intensive orchards in England: A historical note. Acta Horticulturae 114:309-317.

Zimmermann A (1994). Gisela 5, a dwarfing rootstock for sweet cherries from Giessen in a trial. Obstbau 19:62-63. 